\title{
The Mini-Open transpedicular thoracic discectomy: surgical technique and assessment
}

\author{
John H. ChI, M.D., M.P.H., ${ }^{1}$ Sanjay S. Dhall, M.D., ${ }^{2,3}$ Adam S. Kanter, M.D., ${ }^{4}$ \\ and Praveen V. Mummaneni, M.D. ${ }^{2}$
}

${ }^{1}$ Department of Neurosurgery, Brigham \& Women's Hospital, Harvard Medical School; ${ }^{2}$ Department of Neurological Surgery, University of California, San Francisco; ${ }^{3}$ Emory University, Atlanta, Georgia; ${ }^{4}$ Department of Neurological Surgery, University of Pittsburgh, Pennsylvania

\begin{abstract}
Object. Thoracic disc herniations can be surgically treated with a number of different techniques and approaches. However, surgical outcomes comparing the various techniques are rarely reported in the literature. The authors describe a minimally invasive technique to approach thoracic disc herniations via a transpedicular route with the use of tubular retractors and microscope visualization. This technique provides a safe method to identify the thoracic disc space and perform a decompression with minimal paraspinal soft tissue disruption. The authors compare the results of this approach with clinical results after open transpedicular discectomy.

Methods. The authors performed a retrospective cohort study comparing results in 11 patients with symptomatic thoracic disc herniations treated with either open posterolateral (4 patients) or mini-open transpedicular discectomy (7 patients). Hospital stay, blood loss, modified Prolo score, and Frankel score were used as outcome variables.

Results. Patients who underwent mini-open transpedicular discectomy had less blood loss and showed greater improvement in modified Prolo scores $(p=0.024$ and $p=0.05$, respectively) than those who underwent open transpedicular discectomy at the time of early follow-up within 1 year of surgery. However, at an average of 18 months of follow-up, the Prolo score difference between the 2 surgical groups was not statistically significant. There were no major or minor surgical complications in the patients who received the minimally invasive technique.

Conclusions. The mini-open transpedicular discectomy for thoracic disc herniations results in better modified Prolo scores at early postoperative intervals and less blood loss during surgery than open posterolateral discectomy. The authors' technique is described in detail and an intraoperative video is provided.
\end{abstract}

(DOI: 10.3171/FOC/2008/25/8/E5)

\section{KeY WORDS - minimally invasive surgery - thoracic disc - transpedicular discectomy $\bullet$ outcomes}

$\mathrm{S}$ YMPTOMATIC thoracic disc herniations are rare in the general population, yet they represent a distinct challenge for many spine surgeons in practice. They often cause significant radicular pain and severe, progressive myelopathy. Open surgical techniques are effective for the removal of thoracic herniated discs, and include posterolateral approaches (costotransversectomy, transpedicular, lateral extracavitary, and lateral rachiotomy) and lateral approaches (retropleural and transpleural thoracotomy). Unfortunately, to obtain adequate visualization and working space, these approaches require extensive tissue and muscle dissection in excess of the actual area of surgical interest. ${ }^{6,21,24,26}$ Thoracoscopic techniques have also been pioneered, but require a steep learning curve and have gained a limited following among spinal surgeons. ${ }^{2,10,11}$

Recent technical advances that minimize surgical exposure have become popular in the treatment of spinal disorders in the cervical and lumbar spine, but little data has been published regarding such approaches in the thoracic spine. Currently, minimally invasive thoracic disc surgery has not been widely adopted, perhaps due to variations from familiar techniques, differences in the tools used, and in anatomy recognized by practicing spine surgeons..$^{5,7,9,15}$
In our minimally invasive tubular approach to herniated thoracic discs, we position the patient prone, use an operating microscope (instead of an endoscope), and achieve transpedicular decompression with instruments similar to those used for standard lumbar discectomy. We compared surgical and clinical outcomes in patients treated via open and minimally invasive transpedicular thoracic discectomy performed by the senior author (PM).

VIDEO 1. Intraoperative video of the mini-open transpedicular thoracic discectomy.

Windows Media Player/broadband: http://mfile.

akamai.com/21490/wmv/digitalwbc.download.akamai.com/

21492/wm.digitalsource-na-regional/Discectomy02.asx

RealPlayer:

http://mfile.akamai.com/21489/rm/digitalwbc.download.

akamai.com/21492/real.digitalsource-na-regional/

Discectomy02.ram

\section{Surgical Technique \\ Mini-Open Technique}

The patient is positioned prone on a regular operating table on radiolucent bolsters. We use neuromonitoring in these cases and thus limit the use of muscle relaxant. We 


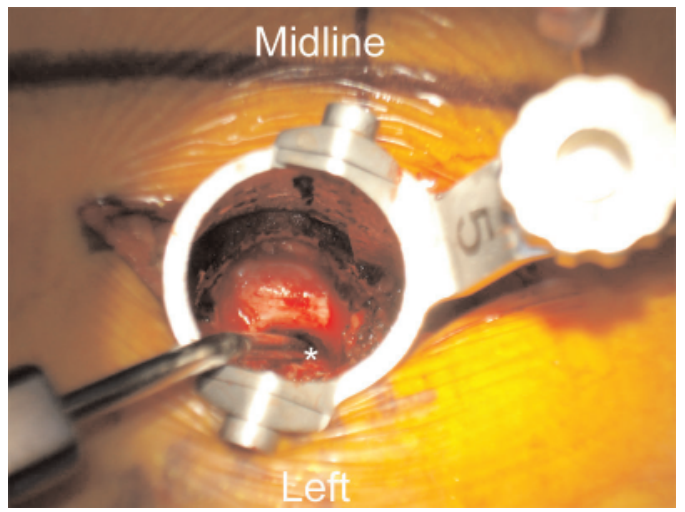

FIG. 1. Intraoperative view. Exposure of the lateral dura, exiting nerve root, and disc space $(*)$ is achieved after removal of the pedicle. Adequate visualization and working room are provided via the expandable tubular retractor. The suction is placed into the resection cavity of the removed thoracic herniated disc.

maintain a mean arterial blood pressure $>90 \mathrm{~mm} \mathrm{Hg}$ to optimize spinal cord perfusion. Localization is performed to center the incision directly over the disc space of interest using fluoroscopy. We use a series of spinal needles placed at intervals to count spinal levels starting at S-1 and marching cranially. After localization, a $3-4 \mathrm{~cm}$ vertical incision overlying the pedicle and disc space of interest is created. The dorsal fascia is opened and extended beyond the limits of the skin incision $(\sim 4-5 \mathrm{~cm})$ to provide more working room in deep tissue. Using the Pipeline (Depuy Spine) or X-tube (Medtronic Sofamor Danek) tubular retractor system, tissue dilation is performed with the dilators positioned perpendicular over the disc space and pedicle of interest. After vertical and lateral tissue dilation (wanding), the tubular retractors are placed and fixed in position to the operating room table. For patients who are relatively thin (retractor depth $<5 \mathrm{~cm}$ ), we use nonexpandable tubes (26$\mathrm{mm}$ width). In larger patients we use an expandable tubular retractor in order to obtain more working room at the depth of the exposure.

The operating microscope is then utilized for the remainder of the procedure. We prefer the operating microscope (instead of the endoscope) because it provides 3D visualization. Intraoperative fluoroscopy aids in maintaining proper localization during exposure and bone decompression. Minimal deep paraspinal muscle resection is needed until the ipsilateral lamina, pars, and facet of the level of interest are clearly identifiable. Once exposure is complete, the thoracic pedicle below the disc space is cannulated in standard fashion using a pedicle probe. It is important to note that in the thoracic spine, the lateral border of the disc space is directly rostral to the pedicle of the vertebral body below. Hemilaminectomy and partial facetectomy can be performed using the cannulated pedicle as a visual landmark. We recommend identification of the thoracic dura mater early during laminectomy so that it can be protected. We do not retract the thoracic cord during the procedure; our disc access is lateral to the spinal cord. Removal of the pedicle just inferior to the disc space is typically required for adequate exposure and access to the disc (Fig. 1). Once the disc space is exposed and identified, the anulus is incised with a No. 15 blade in similar fashion to a lumbar microdiscectomy. Down-biting curettes and micropituitary rongeurs are used to remove the lateral portion of the disc. A cavity is subsequently created in the disc space and the posterior portion of the adjacent vertebral bodies. This key step creates a cavity anterior to the herniated portion of the disc, which is then pushed anteriorly away from the dura and into this cavity. This step eliminates the need for significant thecal sac retraction to access the herniated disc. Unlike the lumbar spine, the thecal sac in the thoracic area cannot be retracted due to the risk of spinal cord injury (Fig. 2 ). Extra care must be taken in partially calcified disc herniations, as these discs can sometimes be adherent to and erode the dura. We do not use this technique for midline, large, calcified herniated discs causing obliteration of the spinal canal (often with erosion of the anterior thoracic dura). We prefer the wider exposure afforded by anterior or open posterolateral approaches for these lesions.

After the decompression is complete, the surgical area is irrigated with antibiotic solution and hemostasis achieved. Placement of a drain is optional. The fascia and skin are closed in standard fashion (we prefer running 3-0 nylon for skin).

\section{Open Posterolateral Technique}

Our open paramedian approach requires a semicircular incision extending 1 level up and down from the disc space of interest with partial transection of the paraspinal muscles so that there is adequate exposure of the lamina, costotransverse joint, and facet complex. Partial exposure of the level above and below is typical to allow for adequate visu-
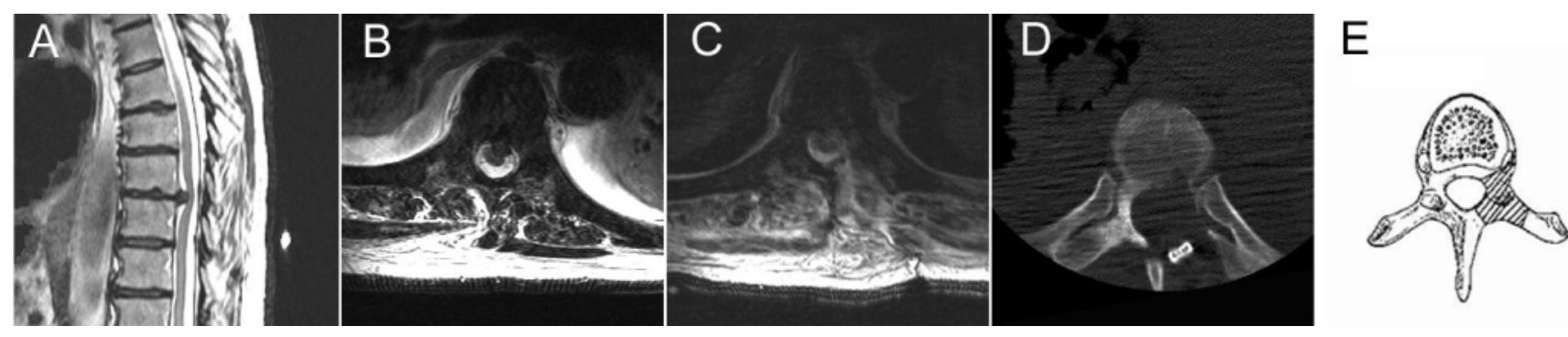

FIG. 2. A and B: Preoperative sagittal (A) and axial (B) T2-weighted MR images demonstrating a large T7-8 herniated disc eccentric to the left. C: Postoperative axial MR image demonstrating removal of disc and decompression of spinal cord via a mini-open transpedicular discectomy. D: Postoperative CT scan showing bone decompression and pedicle removal for access to the disc space (note that a postoperative epidural soft tissue drain was placed). E: Artist's depiction of bone removal (hatched area) performed via a mini-open transpedicular discectomy. 
TABLE 1

Summary of clinical, surgical, and postoperative patient data*

\begin{tabular}{|c|c|c|c|c|c|c|c|c|c|c|c|}
\hline $\begin{array}{l}\text { Age (yrs), } \\
\text { Sex }\end{array}$ & $\begin{array}{l}\text { Spinal } \\
\text { Levels }\end{array}$ & Procedure & $\begin{array}{l}\text { EBL } \\
(\mathrm{ml})\end{array}$ & $\begin{array}{l}\text { LOS } \\
\text { (days) }\end{array}$ & Calcified & Myelopathy & \multicolumn{2}{|c|}{ Prolo Score } & \multicolumn{2}{|c|}{ Frankel Score } & $\begin{array}{l}\text { Length of } \\
\text { FU (mos) }\end{array}$ \\
\hline $77, \mathrm{M}$ & Т8-9 & open & 300 & 4 & yes & yes & 9 & 9 & C & C & 24 \\
\hline $48, \mathrm{M}$ & T11-12 & open & 100 & 3 & no & no & 9 & 12 & $\mathrm{C}$ & D & 24 \\
\hline $58, \mathrm{~F}$ & T11-12 & open & 550 & 4 & yes & yes & 7 & 11 & D & E & 24 \\
\hline $54, \mathrm{M}$ & $\begin{array}{c}\text { T6-7 } \\
\text { T10-11 }\end{array}$ & mini & 340 & 5 & no & yes & 4 & 10 & $\mathrm{C}$ & $\mathrm{D}$ & 15 \\
\hline $49, \mathrm{~F}$ & $\begin{array}{l}\text { T10-11 } \\
\text { T12-L1 }\end{array}$ & $\operatorname{mini}$ & 250 & 2 & no & yes & 14 & 19 & $\mathrm{E}$ & $\mathrm{E}$ & 15 \\
\hline $69, \mathrm{~F}$ & T10-11 & $\operatorname{mini}$ & 150 & 7 & no & yes & 5 & 9 & C & D & 16 \\
\hline $54, \mathrm{~F}$ & T6-7 & $\operatorname{mini}$ & 150 & 2 & no & no & 6 & 14 & $\mathrm{D}$ & $\mathrm{E}$ & 21 \\
\hline $47, \mathrm{M}$ & $\begin{array}{r}\text { T9-10 } \\
\text { T10-11 }\end{array}$ & $\operatorname{mini}$ & 225 & 3 & yes & yes & 7 & 7 & $\mathrm{C}$ & $\mathrm{C}$ & 24 \\
\hline
\end{tabular}

* Abbreviations: $\mathrm{EBL}=$ estimated blood loss; $\mathrm{FU}=$ follow-up; $\mathrm{LOS}=$ length of stay.

alization and working room. Variations of this approach have been previously published by other authors. ${ }^{24,35}$ Apart from the open soft tissue exposure, transpedicular bone decompression and discectomy is performed in essentially identical fashion to the minimally invasive technique we describe here (the hemilamina, facet complex, and pedicle inferior to the disc space are removed with a high-speed drill, and discectomy is performed).

TABLE 2

Modified Prolo Score*

\begin{tabular}{cl}
\hline \hline \multicolumn{1}{c}{ Score } & \multicolumn{1}{c}{ Description } \\
\hline pain & unbearable \\
1 & severe \\
2 & moderate \\
3 & mild \\
5 & none \\
medication & $\geq 10$ hydrocodone tabs or equivalent \\
1 & 6-9 hydrocodone tabs or equivalent \\
2 & $3-5$ hydrocodone tabs or equivalent \\
3 & regular NSAIDs or 1-2 hydrocodone \\
4 & none or occasional hydrocodone \\
5 & \\
functional & total incapacity \\
1 & can do activities at home \\
2 & activities outside home with limits \\
3 & limitations with strenuous activity \\
4 & able to do everything \\
5 & \\
work & unable to do tasks at home \\
1 & able for tasks at home, but unable to work \\
2 & able to perform sedentary work \\
3 & able to work at moderate capacity \\
5 & normal work capacity \\
\hline &
\end{tabular}

* Scale is adapted from Prolo DJ, Oklund SA, Butcher M: Toward uniformity in evaluating results of lumbar spine operations. A paradigm applied to postoperative lumbar interbody fusions. Spine 11:601-606, 1986. Time interval for medication use is a 24 -hour period. A point value is assigned for each category and category points are added for total composite score. NSAID = nonsteroidal antiinflammatory drug.

\section{Methods}

We reviewed the surgical and clinical outcomes in 11 patients who underwent surgery for thoracic disc lesions between 2004 and 2007. All surgeries were performed by the senior author (P.M.). The minimally invasive technique described was used in 7 cases, and the open paramedian approach in 4.

In this series, the average patient age was 56.2 years and there were equivalent numbers of men and women. The most common presenting symptom was back pain, and all patients had radiculopathy; myelopathy was present in $60 \%$ of patients. There were 4 partially calcified herniated discs, 2 in each surgical group. Spinal levels operated on ranged from T-6 to L-1. Four patients underwent surgery at $>1$ thoracic disc level.

Patient characteristics, surgical data, and clinical followup information are presented in Table 1 . We compared estimated blood loss, hospital stay, and the pre- and postoperative modified Prolo scores. Differences in modified Prolo score $^{30,33}$ within treatment cohorts were assessed with the Student t-test for different sample sizes (Table 2).

\section{Results}

The average follow-up period was 18 months (12-24 months). Patients who underwent mini-open transpedicular thoracic discectomy had a mean estimated blood loss of $177 \mathrm{ml}$, while those undergoing the open paramedian approach had a mean estimated blood loss of $337 \mathrm{ml}$ (T-value $=2.71, \mathrm{p}=0.024)$. In our experience, the mini-open technique takes an average of 3 hours and is not longer than the open technique. However, there is a learning curve to this technique. The average hospital stay was shorter for the patients who underwent mini-open transpedicular discectomy (3.5 days versus 4.1 days), but this difference was not statistically significant (Table 3 ).

Modified Prolo scores were obtained in all patients preoperatively within 1 month of surgery and postoperatively during clinic visits for up to 2 years (Table 2). Overall, the modified Prolo scores showed a modest improvement of 
5.1 points. Within 1 year of follow-up, the mini-open group demonstrated an average 6.2-point improvement, which was statistically significant $(\mathrm{T}$-value $=1.72, \mathrm{p}=0.05)$, while the open paramedian group averaged only a 2-point improvement $(\mathrm{T}$-value $=1.09, \mathrm{p}=0.177$; Table 3$)$. However, at 2 years of follow-up, the difference in Prolo scores between the groups was not statistically significant. Frankel scores showed a trend towards improvement in the mini-open group, but this difference was not significant.

\section{Discussion}

Key made the first report of a symptomatic thoracic disc herniation in 1838, although the first recorded attempt to treat a thoracic disc herniation surgically was not until 1922 by Alfred Adson. ${ }^{18,23}$ Initial outcomes from the early experience with surgical treatment via laminectomy were not encouraging, with up to a $32 \%$ rate of neurological worsening after surgery. ${ }^{8,26,34}$ Because laminectomy alone provides limited exposure of the pathological entity, posterolateral approaches were developed to gain more direct surgical access to the area of interest and avoid spinal cord manipulation and injury. Patterson and $\mathrm{Arbit}^{27}$ reported the earliest series of thoracic discs treated via a midline posterior transpedicular approach in 3 patients. The lateral extracavitary approach described by Maiman and colleagues ${ }^{20}$ and costotransversectomy/transpedicular approaches popularized by Fessler et al. and McCormick have become the traditional techniques for thoracic disc removal, and have proven superior to laminectomy with improved safety and clinical outcomes. ${ }^{6,8,21,22}$ However, these open approaches require significant muscle transection and ligamentous detachment, which may contribute to postoperative pain and instability. The transthoracic approach was first introduced by Ransohoff et al. in 1969, ${ }^{31}$ and although clinical outcomes were good, the requirement of an open thoracotomy for adequate exposure was a major disadvantage. ${ }^{1,3,34,35}$ The thoracoscopic approach, pioneered by Dickman and colleagues, provides direct ventral exposure to the disc space and allows for an effective discetomy but requires a high degree of skill, and involves expertise with unfamiliar equipment. , $10,32^{2}$

The advantages of the thoracoscopic approach include short recovery time and avoidance of spinal muscle disruption. Disadvantages to the thoracoscopic approach include difficulty with intraoperative localization, the need to use long, extended instruments, and lack of 3D optics. Additionally, a prerequisite to applying thoracoscopic techniques should be the ability to convert to an open thoracotomy quickly in the event of a complication. Jho and Fessler can be credited with developing the earliest endoscopic posterior-based approach to thoracic discs. ${ }^{12-15,29}$ Their techniques were based on traditional open surgery, but with the use of tubular retractors for exposure and the endoscope for visualization. Clinical results published by both authors demonstrate excellent outcomes. ${ }^{8,12,16,17,25,29}$ Additionally, Maiman and colleagues described a minimally invasive extracavitary approach to thoracic discectomy. ${ }^{19}$

We describe a transpedicular mini-open approach (via a tubular retractor) for thoracic disc herniations that is consistent with the surgical technique most familiar to neurosurgeons for lumbar discectomy. We position the patient prone and use the operative microscope, conferring 3D
TABLE 3

Summary of clinical outcomes*

\begin{tabular}{lccc}
\hline \hline & \multicolumn{3}{c}{ Type of Surgery } \\
\cline { 2 - 4 } \multicolumn{1}{c}{ Parameter } & Open & Mini-Open & p Value \\
\hline average age (yrs) & 61.5 & 52.5 & 0.13 \\
EBL (ml) & 337 & 177 & 0.024 \\
LOS (days) & 4.1 & 3.5 & 0.76 \\
Prolo score change & 2.0 & 6.2 & $0.05 \dagger$ \\
$\quad$ (w/in 12 months) & & & \\
Prolo score change & 4.25 & 5.67 & 0.39 \\
(w/in 24 months) & & & \\
\hline
\end{tabular}

* Differences in modified Prolo scores before and after surgery for both open and mini-open techniques were analyzed using the Student t-test.

$\dagger$ The $\mathrm{p}$ value reported is that for the difference in scores in the mini-open group.

imaging and familiar hand-eye coordination skills. In addition to previously published papers on this topic, we compared both open and mini-open approaches and found significant differences in blood loss and modified Prolo scores.

The main difference between the open and mini-open approaches is the degree to which the soft tissue exposure of the posterior thoracic spine is achieved. In the open approach, the paraspinal muscles are dissected from the spine and partially transected at the level of surgery to gain adequate exposure. Open approaches typically involve a long incision $(7-10 \mathrm{~cm})$. In the mini-open approach, however, the incision is smaller (usually $3-5 \mathrm{~cm}$ ), a musclesplitting tubular retractor is used, and paraspinal muscle attachments are left intact. Partial or complete removal of the pedicle just below the disc space assists in gaining easy and safe access to the disc space. The importance of minimizing muscular and ligamentous trauma to avoid postoperative pain should not be underestimated. The difference in early modified Prolo scores observed in our small study suggests that there may be a real and noticeable difference in outcome when the muscular tension band trauma is minimized. This difference is most noticeable within the first year postoperatively. With a longer follow-up period, the difference observed diminishes, a finding consistent with the evidence that minimally invasive surgery accelerates postoperative recovery without increasing long-term risk compared to traditional approaches.

The ideal use of our mini-open transpedicular approach is in cases of dorsolateral soft disc herniation. In addition, with careful use of short and extended down-pushing curettes, we have found that soft central herniations can also be effectively removed. This approach is not optimal for large, central, calcified discs because of the limited access to the center of the spinal canal afforded by the mini-open transpedicular approach. Central calcified discs represent a difficult problem regardless of the chosen approach; anterior thoracotomy/thoracoscopic or lateral extracavitary approaches with partial corpectomy may be the safest approach for central calcified discs. Transdural herniations are extremely rare and if such a lesion is encountered, we recommend utilizing an open anterior or extended posterolateral approach, which would give the surgeon adequate exposure and working room for intradural, extramedullary spinal surgery and primary dural repair.

Complications in thoracic disc surgery include spinal 
cord injury, postoperative neuralgia, cerebrospinal fluid leak, and postsurgical kyphosis. Intraoperative neuromonitoring with motor evoked potentials and somatosenory evoked potentials is typically utilized in every case. Cerebrospinal fluid leaks are difficult to repair with primarily minimally invasive techniques, but the less disruptive tissue dissection seems to protect the patient from pseudomeningocele development. Postsurgical kyphosis can be an issue, particularly if the pedicle removal and discetomy are performed at the thoracolumbar junction. Supplemental instrumented fixation via percutaneous pedicle screws or pedicle screws placed through the expandable tube can be used to avoid this problem.

Our series is limited in power because of the small sample size, but our technique is an important addition to the contemporary spine surgeon's armamentarium for the treatment of thoracic disc herniations.

\section{Conclusions}

Thoracic disc herniations pose a distinct challenge to most spine surgeons. These lesions can be treated via several surgical trajectories, including posterolateral, lateral, and ventral-lateral approaches. Each approach encompasses varying anatomical considerations and requires different surgical skills. With the advent of "minimally invasive" techniques, thoracic discectomy can be performed via a mini-open transpedicular approach so that tissue trauma is minimized.

\section{Disclosure}

J.H.C. is sponsored by the 2007CNS/Depuy Spine Fellowship Award. P.V.M. is a consultant for Medtronic and DePuy Spine.

\section{References}

1. Birch BD, Desai RD, McCormick PC: Surgical approaches to the thoracolumbar spine. Neurosurg Clin N Am 8:471-485, 1997

2. Connelly CS, Manges PA: Video-assisted thoracoscopic discectomy and fusion. AORN J 67:940-945, 947-948, 950, passim quiz 953-946, 1998

3. Currier BL, Eismont FJ, Green BA: Transthoracic disc excision and fusion for herniated thoracic discs. Spine 19:323-328, 1994

4. Dickman CA, Rosenthal D, Karahalios DG, Paramore CG, Mican CA, Apostolides PJ, et al: Thoracic vertebrectomy and reconstruction using a microsurgical thoracoscopic approach. Neurosurgery 38:279-293, 1996

5. Eichholz KM, O'Toole JE, Fessler RG: Thoracic microendoscopic discectomy. Neurosurg Clin N Am 17:441-446, 2006

6. Fessler RG, Dietze DD Jr, Millan MM, Peace D: Lateral parascapular extrapleural approach to the upper thoracic spine. J Neurosurg 75:349-355, 1991

7. Fessler RG, O'Toole JE, Eichholz KM, Perez-Curet MJ: The development of minimally invasive spine surgery. Neurosurg Clin N Am 17:401-409, 2006

8. Fessler RG, Sturgill M: Review: complications of surgery for thoracic disc disease. Surg Neurol 49:609-618, 1998

9. Foley KT, Lefkowitz MA: Advances in minimally invasive spine surgery. Clin Neurosurg 49:499-517, 2002

10. Han PP, Kenny K, Dickman CA: Thoracoscopic approaches to the thoracic spine: experience with 241 surgical procedures. Neurosurgery 51 (5 Suppl): S88-S95, 2002

11. Horowitz MB, Moossy JJ, Julian T, Ferson PF, Huneke K: Thoracic discectomy using video assisted thoracoscopy. Spine 19: 1082-1086, 1994

12. Isaacs RE, Podichetty VK, Sandhu FA, Santiago P, Spears JD, Aaronson $\mathrm{O}$, et al: Thoracic microendoscopic discectomy: a human cadaver study. Spine 30:1226-1231, 2005
13. Jho HD: Endoscopic microscopic transpedicular thoracic discectomy. Technical note. J Neurosurg 87:125-129, 1997

14. Jho HD: Endoscopic microscopic transpedicular thoracic discectomy. Technical note. Neurosurg Focus 4(2):E7, 1998

15. Jho HD: Endoscopic transpedicular thoracic discectomy. J Neurosurg 91 (2 Suppl):151-156, 1999

16. Jho HD: Endoscopic transpedicular thoracic discectomy. Neurosurg Focus 9(4):E4, 2000

17. Johnson JP, Filler AG, Mc Bride DQ: Endoscopic thoracic discectomy. Neurosurg Focus 9(4):E11, 2000

18. Key CA: On paraplegia depending on disease of the ligaments of the spine. Guys Hospital Rep 3:17-34, 1838

19. Lidar Z, Lifshutz J, Bhattacharjee S, Kurpad SN, Maiman DJ: Minimally invasive, extracavitary approach for thoracic disc herniation: technical report and preliminary results. Spine J 6:157163,2006

20. Maiman DJ, Larson SJ, Luck E, El-Ghatit A: Lateral extracavitary approach to the spine for thoracic disc herniation: report of 23 cases. Neurosurgery 14:178-182, 1984

21. McCormick PC: Retropleural approach to the thoracic and thoracolumbar spine. Neurosurgery 37:908-914, 1995

22. McCormick WE, Will SF, Benzel EC: Surgery for thoracic disc disease. Complication avoidance: overview and management. Neurosurg Focus 9(4):E13, 2000

23. Mixter W, Barr J: Rupture of the intervertebral discs with compression of the spinal cord. New Engl J Med 211:210-215, 1934

24. Mummaneni PV, Rodts GE Jr, Subach BR, Birch BD, Haid RW: Management of thoracic disc disease. Contemporary Neurosurg 23:1-8, 2001

25. Oskouian RJ, Johnson JP: Endoscopic thoracic microdiscectomy. J Neurosurg Spine 3:459-464, 2005

26. Otani K, Yoshida M, Fujii E, Nakai S, Shibasaki K: Thoracic disc herniation. Surgical treatment in 23 patients. Spine 13:12621267, 1988

27. Patterson RH Jr, Arbit E: A surgical approach through the pedicle to protruded thoracic discs. J Neurosurg 48:768-772, 1978

28. Perez-Cruet MJ, Fessler RG, Perin NI: Review: complications of minimally invasive spinal surgery. Neurosurgery 51:S26-36, 2002

29. Perez-Cruet MJ, Kim BS, Sandhu F, Samartzis D, Fessler RG: Thoracic microendoscopic discectomy. J Neurosurg Spine 1: 58-63, 2004

30. Prolo DJ, Oklund SA, Butcher M: Toward uniformity in evaluating results of lumbar spine operations. A paradigm applied to postoperative lumbar interbody fusions. Spine 11:601-606, 1986

31. Ransohoff J, Spencer F, Siew F, Gage L Jr: Transthoracic removal of thoracic disc. Report of three cases. J Neurosurg 31:459-461, 1969

32. Rosenthal D, Dickman CA: Thoracoscopic microsurgical excision of herniated thoracic discs. J Neurosurg 89:224-235, 1998

33. Salehi SA, Tawk R, Ganju A, et al: Transforaminal lumbar interbody fusion: surgical technique and results in 24 patients. Neurosurgery 54:368-374; 2004

34. Simpson JM, Silveri CP, Simeone FA, Balderston RA, An HS: Thoracic disc herniation. Re-evaluation of the posterior approach using a modified costotransversectomy. Spine 18:1872-1877, 1993

36. Stillerman CB, Chen TC, Couldwell WT, Zhang W, Weiss MH: Experience in the surgical management of 82 symptomatic herniated thoracic discs and review of the literature. J Neurosurg 88:623-633, 1998

Manuscript submitted June 15, 2008.

Accepted June 22, 2008.

Address correspondence to: Praveen V. Mummaneni, M.D., Department of Neurosurgery, University of California, San Francisco, 505 Parnassus Ave, M779 Box 0112, San Francisco, California 94143. email: vmum@aol.com. 